\title{
Amphotericin B induced abnormalities in human platelets
}

\author{
K B Pastakia, N E Brownson, D A Terle, B J Poindexter
}

\begin{abstract}
Aims-To investigate in vitro the effect of amphotericin $B$ on platelets in order to understand poor platelet recovery in patients receiving platelet transfusions and amphotericin B simultaneously.

Methods-Washed platelets were isolated from platelet concentrates and exposed to amphotericin $B(4 \mu \mathrm{g} / \mathrm{ml})$ for one hour. Platelet function was assessed by aggregation response to thrombin $(0-0.6 \mathrm{U} / \mathrm{ml})$, serotonin release, response to hypotonic stress, and mean platelet volume. The expression of surface membrane glycoprotein (GP) Ib-IX complex, GPIIb-IIIa complex and CD62P (P-selectin) was examined by flow cytometry using fluorescence labelled monoclonal antibodies. Heterotypic cell adhesion was measured in amphotericin $B$ treated platelets coincubated with isolated, autologous polymorphonuclear leucocytes (PMN) by flow cytometric analysis.
\end{abstract}

Results-Amphotericin B induced platelet dysfunction. The rate of aggregation by thrombin, serotonin uptake and thrombin induced release of serotonin, and the response of platelets to hypotonic stress were inhibited. There was up to a two-fold increase in the mean platelet volume. The expression of platelet surface GPIb-IX and GPIIb-IIIa was not affected. P-selectin, normally expressed only on the surface of activated platelets, was also expressed on unactivated platelets. Amphotericin B increased platelet adherence to PMN and the number of platelets bound per PMN.

Conclusions-In vitro, amphotericin B induces $\mathbf{P}$-selectin expression on the surface of unactivated platelets and increases platelet adhesion to PMN, which is exacerbated by storage. Platelet dysfunction resulting from exposure to amphotericin $B$ may contribute to poor platelet recovery in vivo when amphotericin $B$ is administered concomitantly with platelet transfusion.

(F Clin Pathol: Mol Pathol 1996;49:M301-M307)

Keywords: amphotericin B, platelets, surface membrane glycoprotein, flow cytometry.

of Cellular Hematology,

Division of Hematology,

CBER, Food and Drug

Administration, Building 29

Room 329, 8800 Rockville

Pike, Bethesda, MD 20892,

USA.

Accepted for publication 11 July 1996

Systemic administration of amphotericin B is a standard treatment for mycotic infections. Immunocompromised, critically ill, or patients with cancer often require the simultaneous administration of amphotericin B and blood components. Amphotericin B given concomitantly with platelet transfusion is associated with poor platelet recovery. ${ }^{1-4}$ The recovery of stored platelets 12-18 hours post-transfusion, relative to fresh platelets, decreased from $89 \%$ in clinically stable patients to $65 \%$ in patients receiving intravenous amphotericin $B .{ }^{5}$ In vivo, platelets play a central role in haemostasis by the processes of adhesion and aggregation. Interactions between platelets (haemostatic cells) and inflammatory cells such as polymorphonuclear leucocytes (PMN) are of importance for both haemostasis and inflammation.

Amphotericin B is a lipophilic antibiotic which binds to membrane sterols of mammalian cells, including those in the blood. ${ }^{6}{ }^{7}$ This leads to destruction of membrane integrity, increased cell permeability, leakage of cellular contents, and subsequent cell lysis. In vitro, amphotericin B exacerbates a platelet surface membrane lesion, characterised as "pits", ${ }^{8}$ and decreases the expression of surface membrane glycoprotein (GP) Ib in stored platelets. ${ }^{9}$

In the present study we have characterised the in vitro effects of amphotericin B on platelets. Platelet function was assessed by thrombin induced aggregation, serotonin release, hypotonic stress response, and mean platelet volume. The platelet surface is the primary site of exposure to amphotericin B. We have examined the effect of the antibiotic on the surface expression of platelet membrane GPIb-IX complex, GPIIb-IIIa complex and P-selectin and on platelet-PMN adhesion using flow cytometry.

\section{Methods}

\section{PLATELET PREPARATION}

Platelets were obtained as platelet concentrates by automated plateletpheresis or as platelet rich plasma, from normal human blood collected in 1/11 volume anticoagulant citrate dextrose solution (75 $\mathrm{mM}$ trisodium citrate, $38 \mathrm{mM}$ citric acid, $124 \mathrm{mM}$ dextrose) as described previously. ${ }^{10}{ }^{11}$ Platelet concentrates were stored in polylolefin bags (Fenwal PL732; Baxter Healthcare Corp., Deerfield, Illinois, USA) on a rotator at room temperature $\left(20-24^{\circ} \mathrm{C}\right)$. Incubations in the experiments were carried out at room temperature unless otherwise specified. Washed, unactivated plate- lets were isolated from platelet concentrates or from platelet rich plasma by centrifugation at $1000 \times g$ for 10 minutes in the presence of $1 \mu \mathrm{M}$ prostaglandin $\mathrm{E}_{1}\left(\mathrm{PGE}_{1}\right)$ and resuspen- 
sion at a density of $5 \times 10^{8} / \mathrm{ml}$ in Tyrode'sHEPES buffer (TH; $137 \mathrm{mM} \mathrm{NaCl}, 2.7 \mathrm{mM}$ $\mathrm{KCl}, \quad 0.42 \mathrm{mM} \mathrm{NaH}_{2} \mathrm{PO}_{4}, 12.5 \mathrm{mM}$ $\mathrm{NaHCO}_{3}, \quad 2.0 \quad \mathrm{mM} \quad \mathrm{MgCl}_{2}, \quad 5.5 \mathrm{mM}$ D-glucose, $5.0 \mathrm{mM} \mathrm{HEPES}$, and $3.5 \mathrm{mg} / \mathrm{ml}$ bovine serum albumin, $\mathrm{pH}$ 7.4).

\section{AMPHOTERICIN B TREATMENT}

Amphotericin B (Life Technologies, Gaithersburg, Maryland, USA), $250 \mu \mathrm{g} / \mathrm{ml}$ stock solution in saline, was added at a final concentration of $4 \mu \mathrm{g} / \mathrm{ml}$ to the platelet suspension in TH buffer. Platelets were incubated with the antibiotic at $37^{\circ} \mathrm{C}$ for one hour. An equal volume of saline was added to control samples. The concentration of $4 \mu \mathrm{g} / \mathrm{ml}$ amphotericin B was chosen for study as representative of therapeutic peak serum concentrations reported with intravenous amphotericin $\mathrm{B}^{78}$ In preliminary experiments, thrombin induced platelet aggregation was studied after treatment with 1 , 2 and $4 \mu \mathrm{g} / \mathrm{ml}$ amphotericin $\mathrm{B}$ and the mean platelet volume was determined after treatment with $1-32 \mu \mathrm{g} / \mathrm{ml}$ amphotericin $B$.

PLATELET COUNTING AND SIZE ANALYSIS

Platelet counts and size analysis were performed on a System 9000 Hematology Series cell counter (Serono Baker Diagnostics, Allentown, Pennsylvania, USA). The mean platelet volume was used to assess shifts in platelet size.

\section{PLATELET AGGREGATION}

Amphotericin $B$ treated platelets and untreated controls $(150 \mu \mathrm{l})$ were incubated in a microtitre plate with human $\alpha$-thrombin (lot H2; FDA, Bethesda, Maryland, USA) added at concentrations of $0.18-0.6 \mathrm{U} / \mathrm{ml}$. Aggregation was monitored as a change in the absorbance at $650 \mathrm{~nm}\left(\mathrm{~A}_{650}\right)$ using a Vmax Kinetic Microplate Reader (Molecular Devices Corporation, Menlo Park, California, USA). ${ }^{12}$

HYPOTONIC STRESS RESPONSE

Platelets $\left(50 \mu \mathrm{l}\right.$ of $\left.1 \times 10^{9} / \mathrm{ml}\right)$ treated with 4 $\mu \mathrm{g} / \mathrm{ml}$ amphotericin $\mathrm{B}$ or untreated, control platelets were added to $100 \mu \mathrm{l} \mathrm{TH}$ (buffer controls, -stress) or $100 \mu \mathrm{l}$ distilled water (+stress). Hypotonic stress response was measured as a change in $A_{650}$ with time using a Vmax Kinetic Microplate Reader.

\section{SEROTONIN UPTAKE AND RELEASE ASSAY}

Serotonin release was assayed as described previously. ${ }^{13}$ Amphotericin B treated platelets and controls $\left(5 \times 10^{8} / \mathrm{ml}\right)$ were incubated with $0.05 \mu \mathrm{Ci} / \mathrm{ml}\left[{ }^{14} \mathrm{C}\right]$ serotonin (New England Nuclear, Boston, Massachusetts, USA) for 30 minutes at $37^{\circ} \mathrm{C}$. Samples were washed once in TH buffer with $1 \mu \mathrm{M} \mathrm{PGE}_{1}$ and resuspended in TH buffer at $5 \times 10^{8} / \mathrm{ml}$. An aliquot was used to measure the extent of serotonin uptake by scintillation counting. Imipramine $(6.8 \mu \mathrm{M})$ was added to the final platelet suspension to prevent re-uptake of serotonin following thrombin stimulation. Aliquots $(1 \mathrm{ml})$ were activated by $0.02-4.0 \mathrm{U} / \mathrm{ml}$ thrombin for two minutes. Platelets were then fixed by adding
$2.5 \mathrm{ml}$ cold $1.5 \mathrm{M}$ formaldehyde and incubation at $4{ }^{\circ} \mathrm{C}$ for 10 minutes. The platelet suspension was centrifuged at $3200 \times g$ and the serotonin released from platelets was measured in the supernatant. The serotonin release at various thrombin concentrations was expressed as a percent of the total extent of serotonin uptake in the platelets.

PMN ISOLATION

PMN were isolated from autologous human blood as described previously. ${ }^{14}$ Briefly, PMN were isolated by dextran sedimentation, density gradient centrifugation using Lymphocyte Separation Medium (Organon Teknika, Durham, North Carolina, USA) and hypotonic lysis of erythrocytes. PMN were washed three times with and resuspended in calcium- and magnesium-free Hank's balanced salt solution (HBSS; Life Technologies) to $10^{7} / \mathrm{ml}$.

ANTIBODIES

The fluorescein isothiocyanate (FITC) conjugated CD41 monoclonal antibody (clone P2; Immunotech Inc., Westbrook, Maine, USA) recognises an epitope on GPIIb only present on the platelet membrane GPIIb-IIIa complex. The phycoerythrin (PE) conjugated CD62P monoclonal antibody (clone AC1.2; Becton Dickinson Immunocytometry Systems, San Jose, California, USA) recognises the CD62P (P-selectin) antigen, an $\alpha$-granule membrane protein that is externalised and expressed on the plasma membrane of activated platelets. The GPIb-IX monoclonal antibody (Immunotech Inc.) recognises an epitope only present on the platelet membrane GPIb-IX complex. This monoclonal antibody was labelled with secondary goat anti-mouse IgG-FITC antiserum (Sigma, St Louis, Missouri, USA). All of the monoclonal antibodies are of the IgG class. The isotype control reagents conjugated to either FITC or PE were purchased from Becton Dickinson Immunocytometry Systems.

\section{PREPARATION OF PLATELETS FOR FLOW}

CYTOMETRY

Labelling of platelets with monoclonal antibodies was carried out as described previously. ${ }^{9}$ Amphotericin B treated platelets were diluted to $5 \times 10^{7} / \mathrm{ml}$ in $\mathrm{TH}$ buffer containing either 5 mM EDTA for assessing monoclonal antibody binding to GPIb-IX or $2 \mathrm{mM} \mathrm{CaCl}{ }_{2}$ (TH-Ca) for binding to GPIIb-IIIa and P-selectin. Aliquots $(100 \mu \mathrm{l})$ were incubated with saturating concentrations of monoclonal antibody. Thrombin $(0.032-4.0 \mathrm{U} / \mathrm{ml})$ was added and samples were incubated for 30 minutes. After 15 minutes, a saturating concentration of goat antimouse IgG-FITC secondary antibody was added to samples in which unlabelled GPIb-IX monoclonal antibody was used. The samples were then fixed with an equal volume of $2 \%$ formaldehyde in $\mathrm{TH}$ buffer for 30 minutes. The samples were diluted to $0.5 \mathrm{ml}$ in $\mathrm{TH}$ buffer and analysed using flow cytometry. 


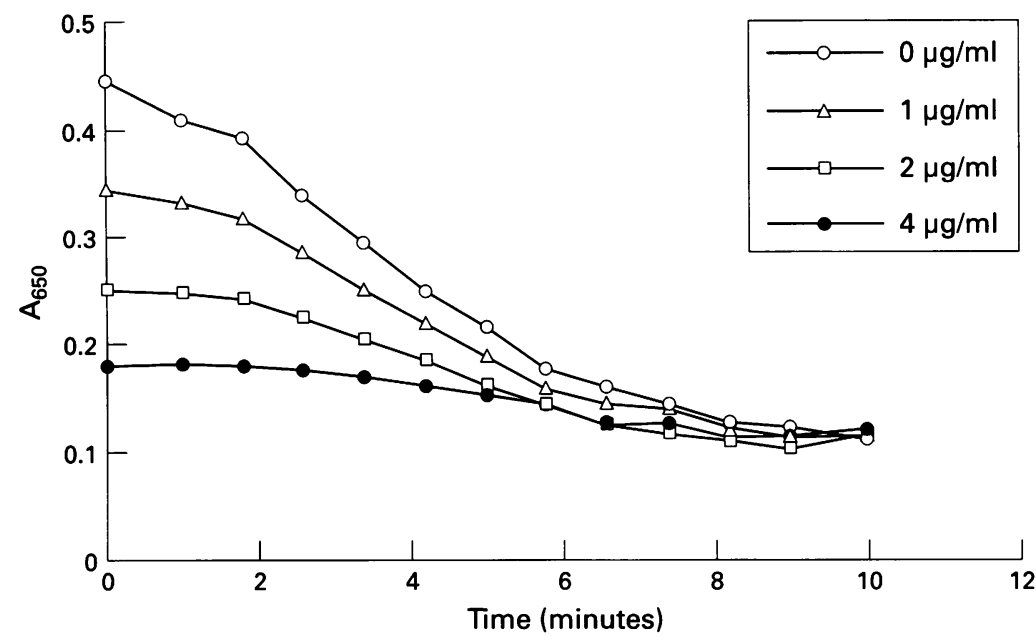

Figure 1 Thrombin induced platelet aggregation after exposure for one hour to amphotericin B. Platelets $\left(5 \times .10^{8} / \mathrm{ml}\right)$ in TH were incubated with $0,1,2$, or $4 \mu \mathrm{g} / \mathrm{ml}$ amphotericin $B$ at $37^{\circ} \mathrm{C}$ and stimulated with thrombin $(0.18 \mathrm{U} / \mathrm{ml})$. Aggregation was measured as changes in light absorption $\left(A_{650}\right)$ following addition of thrombin at time 0 minutes.

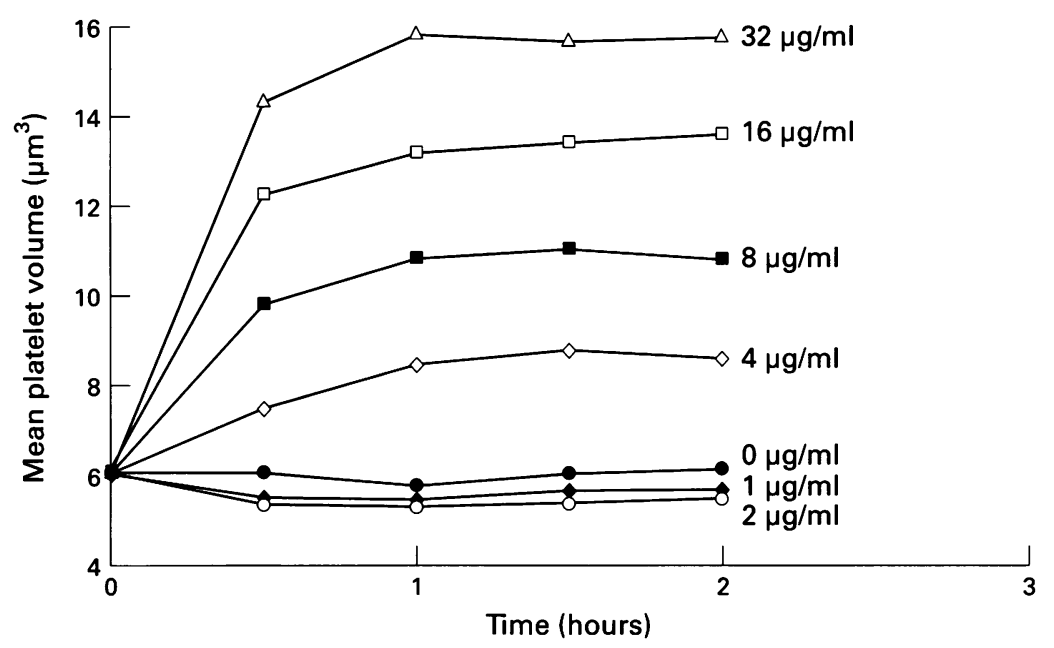

Figure 2 Effect of amphotericin $B$ on mean platelet volume. Platelets $\left(5 \times 10^{8} / \mathrm{ml}\right)$ in $T H$ were incubated with $0,1,2,4,8,16$, and $32 \mu \mathrm{g} / \mathrm{ml}$ amphotericin $B$ for one hour at $37^{\circ} \mathrm{C}$ and the mean platelet volume was measured in a cell counter. events below the threshold) for positive platelet fluorescence. The platelet fluorescence ratio, an estimate of the number of platelets bound to each neutrophil, was determined as described by Rinder et al. ${ }^{15}$ The experiments were performed at least three times with single representative experiments shown in figs 5, 6 and 7.

\section{STATISTICAL ANALYSIS}

The data were analysed using a paired $t$ test. Values are expressed as mean (SD). Differences were considered significant if $\mathrm{p}<0.05$.

\section{Results}

\section{PLATELET AGGREGATION}

Exposure of platelets in TH buffer to increasing amphotericin $\mathrm{B}$ concentrations from 1 to 4 $\mu \mathrm{g} / \mathrm{ml}$ for one hour at $37^{\circ} \mathrm{C}$ resulted in a decrease in their $A_{650}$ (fig 1). Increasing amphotericin $B$ concentrations inhibited the thrombin induced rate of aggregation by $20-70 \%$. The inhibitory effect of amphotericin $B$ was observed at $0.18 \mathrm{U} / \mathrm{ml}$ thrombin (fig 1) and similarly at higher thrombin concentrations up to $0.6 \mathrm{U} / \mathrm{ml}$ (data not shown). The extent of aggregation was not affected. Examination by light microscopy of untreated platelets and platelets treated with $1-4 \mu \mathrm{g} / \mathrm{ml}$ amphotericin B did not reveal any notable difference in morphology.

\section{MEAN PLATELET VOLUME}

The effect on mean platelet volume of exposing platelets in TH buffer to varying concentrations of amphotericin B is shown in fig 2 . In the presence of $4-32 \mu \mathrm{g} / \mathrm{ml}$ amphotericin B the mean platelet volume increased 1.4-2.6 fold. Platelet count was not affected. Platelets, after five days of storage, showed similar increases in the mean platelet volume on treatment with amphotericin B under the same conditions (data not shown).

\section{HYPOTONIC STRESS RESPONSE}

PLATELET-PMN CO-INCUBATION ASSAY

Fixed, CD41-FITC labelled platelets $(150 \mu \mathrm{l}$, $3 \times 10^{8} / \mathrm{ml}$ ) in $\mathrm{TH}-\mathrm{Ca}$ buffer were added to viable PMN $\left(150 \mu \mathrm{l}, 3 \times 10^{6} / \mathrm{ml}\right)$ to approximate the relative densities in normal blood, mixed by gentle inversion, incubated for 30 minutes, and analysed using flow cytometry.

\section{FLOW CYTOMETRY}

A FACScan flow cytometer (Becton Dickinson Immunocytometry Systems) was used to acquire logarithmically amplified light scatter and fluorescence signals from 10000 platelets in each sample. Platelets and PMN were identified by their characteristic forward and orthogonal light scatter and by CD41-FITC fluorescence as a platelet specific marker. Results are expressed as histograms of cell count versus log fluorescence intensity ( $\mathrm{FLl}$ or FL2) or bar graphs. Background binding, obtained from parallel assays with FITC or PE labelled isotype control monoclonal antibodies, was used to set a threshold ( $99 \%$ of control
Hypotonic stress response was inhibited in platelets exposed to $4 \mu \mathrm{g} / \mathrm{ml}$ amphotericin $\mathrm{B}$, as shown in fig 3. The $A_{650}$ of amphotericin $B$ treated platelets was lower than the untreated platelets. Under hypotonic stress, the $A_{650}$ of the untreated platelets decreased initially and then increased, indicating partial recovery. The platelets exposed to antibiotic and subjected to hypotonic stress showed a decrease in $\mathrm{A}_{650}$, which remained unchanged with time.

\section{SEROTONIN UPTAKE AND RELEASE}

Amphotericin B strongly inhibited (85 (5)\%) total $\left[{ }^{14} \mathrm{C}\right]$ serotonin uptake, as determined by scintillation counting. Serotonin release in amphotericin B treated platelets is also inhibited upon activation by thrombin (fig 4). The maximum serotonin released, at the highest thrombin concentration $(4.0 \mathrm{U} / \mathrm{ml})$, indicated that in control platelets 79 (3)\% of total serotonin uptake was releasable, whereas in amphotericin B treated platelets 55 (9)\% of total uptake was releasable. 
0.4

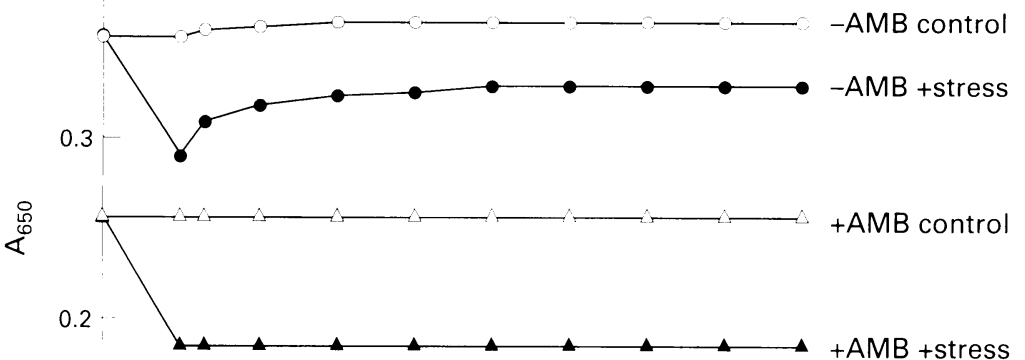

0.1

46

6

Time (minutes)

Figure 3 Hypotonic shock response of platelets exposed to amphotericin B. Platelets $(50 \mu$ of $\left.1 \times 10^{4} / \mathrm{ml}\right)$ in $\mathrm{TH}$ buffer untreated $(-A M B)$ or treated with $4 \mu \mathrm{g} / \mathrm{ml}$ amphotericin $B$ $(+A M B)$ were added to $100 \mu l \mathrm{TH}$ buffer (control) or $100 \mu l$ distilled water (+stress). Hypotonic stress response was measured as changes in light absorption $\left(A_{650}\right)$ with time. $A M B=$ amphotericin $B$.
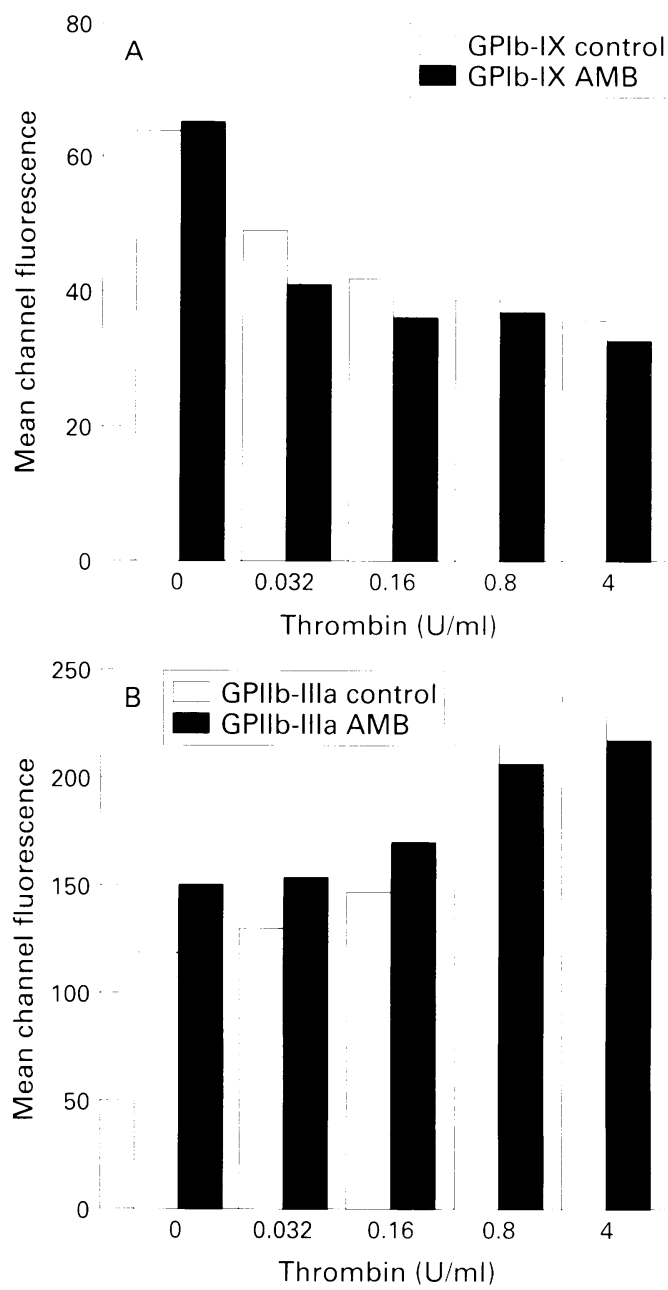

Figure 4 Serotonin release in amphotericin B treated platelets. Thrombin induced serotonin release is illustrated as the per cent of $\left[{ }^{1+} C\right]$ serotonin loaded into platelets. Control without amphotericin $B(A M B)$ treatment () ; platelets treated with $4 . \mathrm{ug} / \mathrm{ml}$ amphotericin $B(\bullet)$.

SURFACE EXPRESSION OF MEMBRANE

GLYCOPROTEINS

Thrombin induced a decrease in surface GPIb-IX expression and an increase in GPIIbIIIa expression in control and amphotericin B treated platelets (figs 5A and 5B). In fresh, unactivated platelets exposed to amphotericin B surface P-selectin was elevated compared with fresh, control platelets which do not express P-selectin (fig 5C). P-selectin expression was increased by thrombin concentrations of $0.16-4.0 \mathrm{U} / \mathrm{ml}$ in both control and amphotericin B treated platelets. Its expression was higher in treated platelets than in untreated ones at low thrombin $(0.032$ and $0.16 \mathrm{U} / \mathrm{ml})$ concentrations.

The effect of amphotericin B on surface P-selectin expression in stored platelets is shown in fig 6 . Surface P-selectin expression was undetectable in fresh platelets but increased with amphotericin B treatment (fig 6A). In five-day stored platelets, surface P-selectin expression was observed in untreated platelets and was significantly increased in amphotericin B treated platelets (fig 6B).

ADHESION OF PLATELETS TO PMN

Isolated platelets and PMN were co-incubated as described. Figure 7 shows the histograms of

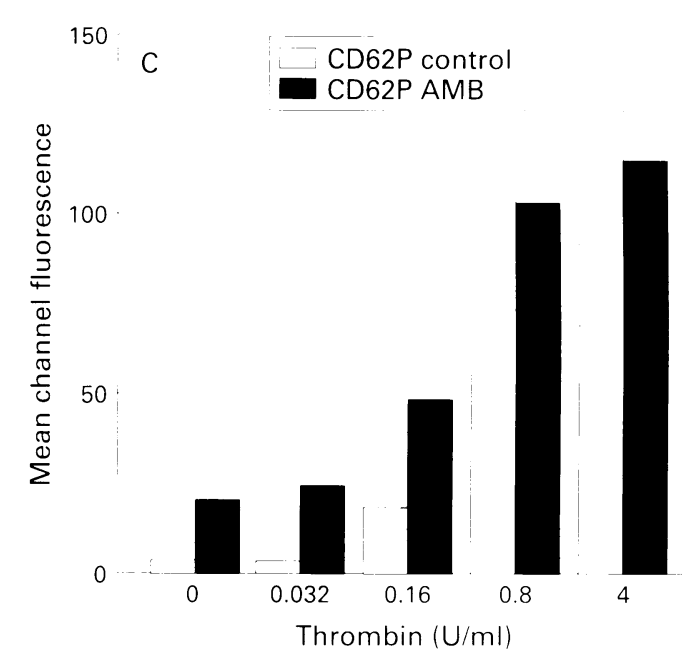

Figure 5 Effect of amphotericin B (AMB) on thrombin dependent expression of platelet membrane glvcoproteins as determined by flow cytometry. Plateles in TH buffor without amphotericin $B$ (open bars) or with + ugml amphotericin $B$ (shaded bars) were incubated at $37^{\circ} \mathrm{C}$ for one hour. Monoclonal antibodies were added and the platelets stimulated with 0.32-4.0 U/ml thrombin for 30 minutes before fixing. Bar graphs illustrate (A) GPIb-IX, (B) GPIIb-III and (C) CD62P expression as mean channel fluorescence. This experiment is representative of three separate experiments.

a representative assay of the effect of amphotericin B on platelet adhesion to PMN. The platelets were labelled with anti-GPIIb-IIIaFITC monoclonal antibody. PMN events positive for the platelet marker fluorescence represent PMN with bound platelets. A threshold marker for platelet fluorescence was set using 

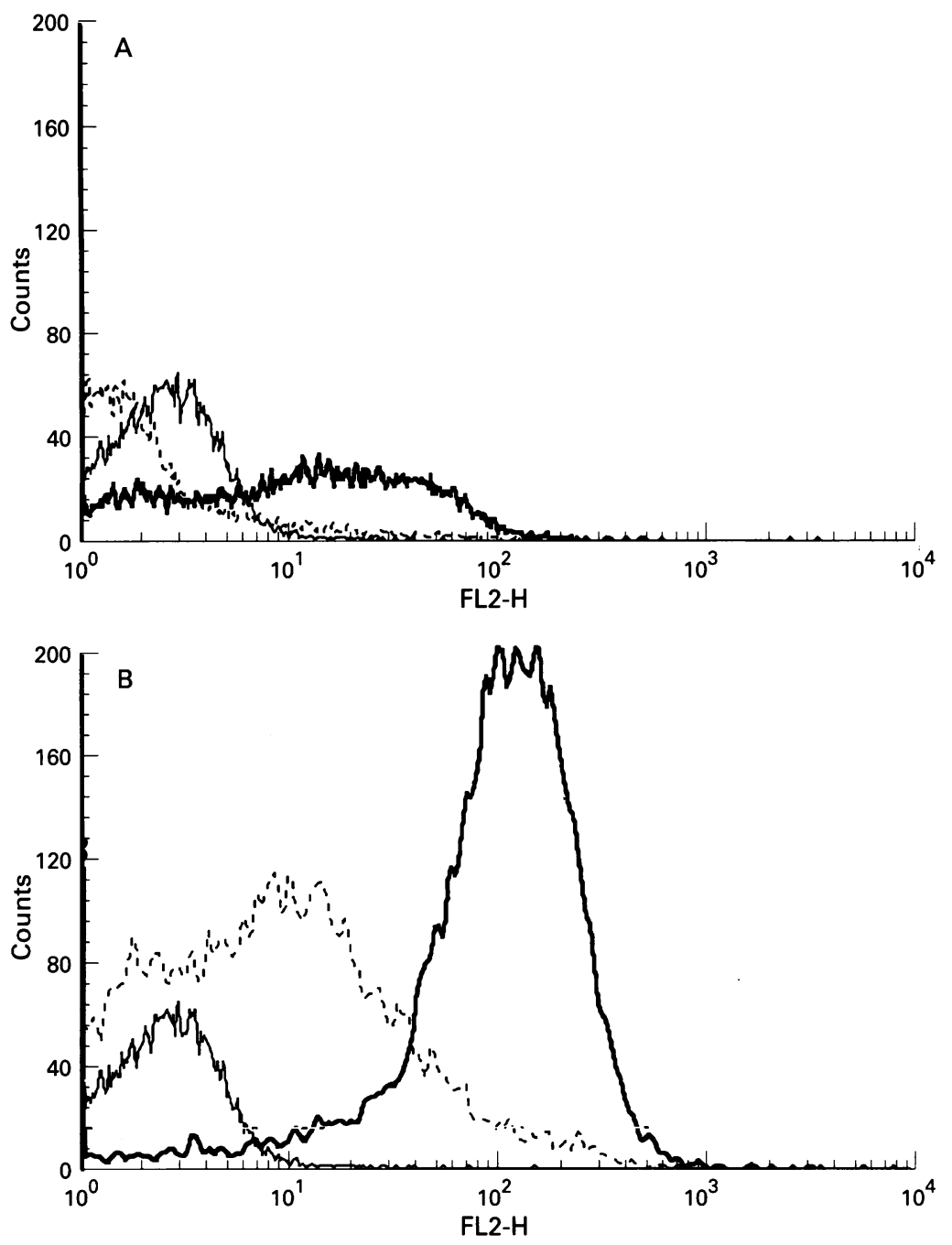

Figure 6 Effect of five-day storage on surface P-selectin expression in amphotericin $B$ treated platelets. Platelets isolated from fresh $(A)$ or five-day stored platelet concentrates $(B)$ were suspended at $5 \times 10^{7} / \mathrm{ml}$ in $\mathrm{TH}-\mathrm{Ca}$ buffer, with or without $4 \mu \mathrm{g} / \mathrm{ml}$ amphotericin $B$.

The samples were labelled with PE conjugated P-selectin monoclonal antibody or an isotype control monoclonal antibody, fixed with $2 \%$ formaldehyde and analysed using flow cytometry. In both panels, the thin line histogram plots correspond to the isotype control (mouse IgG-PE) used to set the threshold marker for positive platelet fluorescence. The threshold excluded $99 \%$ of the isotype control fluorescence. The dashed lines correspond to fresh platelets $(A)$ or stored platelets $(B)$ without amphotericin B treatment labelled with $P$-selectin monoclonal antibody. The bold lines correspond to fresh platelets $(A)$ or stored platelets $(B)$ treated with amphotericin $B$ and labelled with $P$-selectin monoclonal antibody. This experiment is representative of three separate experiments.

an isotype control (figs $7 \mathrm{~A}$ and $\mathrm{B}$; thin lines); events with fluorescence levels above this threshold represent PMN with bound platelets.

Amphotericin B increased platelet adherence to PMN as shown by the increase in the percentage of PMN which had platelets bound and the number of platelets bound per PMN. In the representative experiment (fig 7), unactivated platelets co-incubated with PMN resulted in $41 \%$ of PMN having adhered platelets (fig $7 \mathrm{~A}$; dashed line), whereas $73 \%$ of PMN bound amphotericin B treated, unacti-

Table 1 Heterotypic adhesion of platelets to PMN. Results are expressed as mean (SD)

\begin{tabular}{llllll}
\hline & \multicolumn{2}{l}{ PMN binding platelets (\%) } & & \multicolumn{2}{l}{ Platelet fluorescence ratio } \\
\cline { 2 - 3 } & Unactivated & Activated & & Unactivated & Activated \\
\hline Control & $52(11)$ & $99(1)$ & & $2(1)$ & $10(3)$ \\
Amphotericin B & $83(10)$ & $89(10)$ & & $9(1)$ & $9(1)$ \\
\hline
\end{tabular}

vated platelets (fig 7A; bold line). Thrombin activated platelets, untreated or treated with amphotericin $\mathrm{B}$, were bound by $98 \%$ and $80 \%$ of PMN, respectively (fig $7 \mathrm{~B}$; dashed and bold lines). Exposure of platelets to amphotericin B increased the number of unactivated platelets bound per PMN-that is, the mean platelet fluorescence ratio, from 2 to 9 . The mean platelet fluorescence ratios of PMN binding activated platelets without and with amphotericin $B$ were 10 and 9 , respectively. The results of three experiments are summarised in table 1. The percentage of PMN binding unactivated platelets was significantly increased by treatment with amphotericin B ( $p<0.003)$. Thrombin activation of untreated and treated platelets also increased the percentage of PMN binding platelets $(p<0.009)$. The platelet fluorescence ratio increased upon amphotericin $B$ treatment of unactivated platelets $(p<$ 0.004). Thrombin activation of untreated platelets increased the platelet fluorescence ratio $(\mathrm{p}<0.02)$

\section{Discussion}

Simultaneous administration of amphotericin $B$ with transfusion of stored platelets induces an impressive decrease in in vivo platelet recovery and survival in myelosuppressed patients. ${ }^{5}$ In our in vitro studies we examined the effect of amphotericin B on platelet function and the expression of surface membrane glycoprotein in fresh and stored platelets. Exposure of washed platelets to therapeutic concentrations of amphotericin B $(4 \mu \mathrm{g} / \mathrm{ml})$ for one hour resulted in impaired function in both fresh and stored platelets. The rate of aggregation by thrombin, serotonin uptake and release, and response to hypotonic stress were inhibited, and the mean platelet volume was increased. Amphotericin B binds to sterols of mammalian cell membranes and functions as an ionophore, inducing extensive permeability to ions. ${ }^{6}$ Such an effect on the platelet membranes could result in the observed increase in the mean platelet volume on treatment with amphotericin B. The inhibition of serotonin uptake observed by us, could be the result of disruption of the transmembrane proton, $\mathrm{Na}^{+}$, and $\mathrm{K}^{+}$gradients which are required for active transport of serotonin across the platelet plasma membrane. ${ }^{16}$ Inhibition of serotonin release may be because of its lower uptake on exposure to amphotericin B. Exposure of red blood cells to amphotericin B in vitro causes cell lysis subsequent to disruption of membrane permeability. ${ }^{17}$ However, in vivo increased cation pumping by healthy red cells compensates for the damage. Administration of amphotericin B with granulocyte transfusion has been reported to cause lethal pulmonary reactions, possibly from PMN lysis and release of proteases that damage the tissue. ${ }^{18}$ A more recent study, ${ }^{19}$ however, showed no detrimental interaction between granulocyte transfusion and amphotericin B. Studies of platelets using scanning electron microscopy show a significant increase in "pit" formation in stored platelets exposed to 

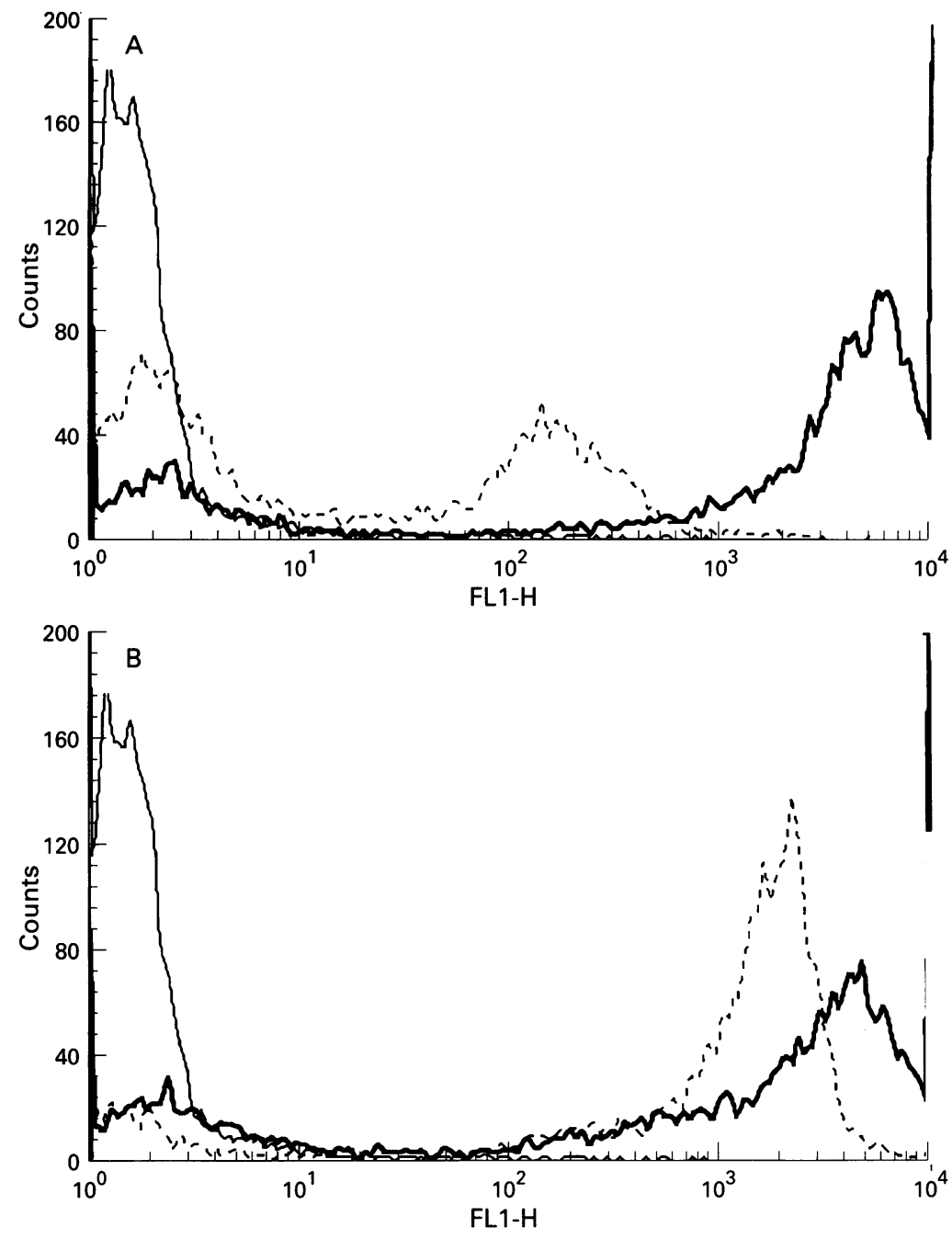

Figure 7 Flow cytometric analysis of the effect of amphotericin $B$ on platelet-PMN adhesion. Platelets in $T H$ buffer were treated with amphotericin $B$, labelled with platelet specific, FITC conjugated CD41 (GPIIb-IIIa) monoclonal antibody or an isotype control antibody (mouse IgG-FITC), activated with thrombin $(0.2 \mathrm{U} / \mathrm{ml})$ and fixed. Platelets and PMN were then co-incubated for 30 minutes. Events in the PMN gate which were platelet marker positive were analysed. In $(A)$ and $(B)$ the thin line histogram plots correspond to $P M N$ events labelled with the isotype control (mouse IgG-FITC) used to set the threshold for positive platelet fluorescence. Histogram plots in $(A)$ correspond to untreated (dashed line) and amphotericin $B$ treated (bold line) unactivated platelets adhered to PMN.

Histogram plots in (B) correspond to untreated (dashed line) and amphotericin $B$ treated (bold line) activated platelets adhered to PMN. This experiment is representative of four separate experiments. expression was increased notably upon amphotericin B treatment compared with amphotericin B treated fresh platelets. P-selectin expression on the platelet surface membrane is a marker of platelet activation and its expression on platelet surface membranes has been shown to correlate with storage ${ }^{22}$ and reduced recovery one hour post-transfusion. ${ }^{23}{ }^{24}$ The reduced recovery and survival observed with simultaneous administration of stored platelets and amphotericin B in certain clinical conditions may result from increased P-selectin expression on the platelet surface that occurs during storage, being exacerbated by exposure to the antibiotic. Novel approaches have been developed recently to improve the delivery of amphotericin B. The administration of liposomal amphotericin B preparations has an improved toxicity profile compared with the standard preparation. ${ }^{7}$ Other antifungals increasingly used as alternatives to amphotericin B for treatment of systemic fungal infection include ketoconazole and fluconazole.?

Adhesion of unactivated platelets to PMN was increased in amphotericin B treated platelets probably because of the surface expression of P-selectin which mediates platelet-PMN adhesion via the P-selectin glycoprotein ligand-1 receptor on the PMN surface. ${ }^{25-27}$ Surface expression of $\mathrm{P}$-selectin is increased in stored platelets. ${ }^{22}$ Exacerbation of this platelet storage lesion by amphotericin B could lead to increased binding of platelets to leucocytes which may be a potent mechanism in vivo for the clearance of platelets transfused concomitantly with amphotericin B from the circulation.

1 Kulpa J, Zaroulis CG, Good RA, Kutti J. Altered platelet function and circulation induced by amphotericin $B$ in leukemic patients after platelet transfusion. Transfusion 1981;21:74-6.

2 Bishop JF, McGrath K, Wolf MM, Matthews JP, DeLuise T, Holdsworth $\mathrm{R}$, et al. Clinical factors influencing the efficacy of pooled platelet transfusions. Blood 1988;71:383-7.

3 Murphy S. Amphotericin B and platelet transfusion. Transfusion 1992;32:7-8.

4 Ezzone S. Can amphotericin B and blood components be given simultaneously? ONS News 1995;10:6.

5 Norol F, Kuentz M, Cordonnier C, Beaujean F, Haioun C Norol F, Kuentz M, Cordonnier C, Beaujean F, Haioun C,
Vernant JP, et al. Influence of clinical status on the efficiency of stored platelet transfusion. $\mathrm{Br} f$ Haematol 1994;86:125-9.

6 Gary-Bobo CM. Polyene-sterol interaction and selective toxicity. Biochimie 1989;71:37-47.

7 Terrell CL, Hughes CE. Antifungal agents used for deep-seated mycotic infections. Mayo Clin Proc 1992;67: 69-91.

8 McGrath K, Bertram JF, Houghton S, Boothman J, Manderson JA, Minchinton R. Amphotericin B-induced
injury in stored human platelets. Transfusion 1992;32:46-50.

9 Sloand EM, Kumar P, Yu M, Klein HG. Effect of AmphoSloand EM, Kumar P, Yu M, Klein HG. Effect of Ampho-
tericin B and fluconazole on platelet membrane glycoproteins. Transfusion 1994;34:415-20.

10 Pastakia KB, Terle D, Prodouz KN. Penicillin-induced dysfunction of platelet membrane glycoproteins. $\mathcal{F}$ Lab Clin Med 1993;121:546-54.

11 Pastakia KB, Brownson NE, Terle DA, Harvath L. Adhesion of platelets to chemotactically responsive and nonresponsive neutrophils. F Clin Pathol: Mol Pathol 1996;49: M17-22.

12 Fratantoni JC, Poindexter BJ. Measuring platelet aggregation with microplate reader: a new technical approach to platelet aggregation studies. Am f Clin Pathol 1990;94: 613-17.

13 Fratantoni JC, Poindexter BJ. Characterization of the platelet response to exogenous arachidonic acid. Throm Res 1981;22:157-66.

14 Harvath L, Balke JA, Christiansen NP, Russell AA, Skubitz KM. Selected antibodies to leukocyte common antigen (CD45) inhibit human neutrophil chemotaxis. F Immunol 1991;146:949-57.

15 Rinder HM, Bonan JL, Rinder CS, Ault KA, Smith BR Activated and unactivated platelet adhesion to monocytes and neutrophils. Blood 1991;78:1760-9. lets, ${ }^{21}$ was expressed on the surface of unact vated platelets exposed to amphotericin $B$. In five-day stored platelets surface P-selectin 
16 Keyes SR, Rudnick G. Coupling of transmembrane proton gradients to platelet serotonin transport. $\mathcal{F}$ Biol Chem 1982; 257:1172-6.

17 Blum SF, Shohet SB, Nathan DG, Gardner FH. The effect of amphotericin $\mathrm{B}$ on erythrocyte membrane cation permeability: its relation to in vivo erythrocyte survival. $\mathcal{f}$ Lab Clin Med 1969;73:980-7.

18 Wright DG, Robichaud KJ, Pizzo PA, Deisseroth AB. Lethal pulmonary reactions associated with the combined use of amphotericin B and leukocyte transfusions. $N$ Engl $\mathcal{F} \mathrm{Med}$ 1981;304:1 185-9.

19 Dutcher JP, Kendall J, Norris D, Schiffer C, Aisner J, Wiernik PH. Granulocyte transfusion therapy and amphoWiernik PH. Granulocyte transfusion therapy and ampho-
tericin B: adverse reactions? Am f Hematol 1989;31:102-8.

20 Michelson AD, Barnard MR. Thrombin-induced changes in platelet membrane glycoproteins Ib, IX, and IIb-IIIa complex. Blood 1987;70:1673-8.

21 Berman CL, Yeo EL, Wencel-Drake JD, Furie BC Ginsburg MH, Furie B. A platelet alpha granule membran protein that is associated with the plasma membrane after activation. $\mathcal{F}$ Clin Invest 1986;78:130-7.

22 Rinder HM, Snyder EL, Bonan JL, Napychank PA, Malkus
$H$. Smith BR Activation in stored platelet concentrates: correlation between membrane expression of P-selectin, glycoprotein IIb/IIIa, and $\beta$-thromboglobulin release. Transfusion 1993;33:25-9.

23 Rinder HM, Murphy M, Mitchell JG, Stocks J, Ault KA, Hillman RS. Progressive platelet activation with storage: evidence for shortened survival of activated platelets after transfusion. Transfusion 1991;31:409-14.

24 Triulzi DJ, Kickler TS, Braine HG. Detection and significance of alpha granule membrane protein 140 expression on platelets collected by apheresis. Transfusion 1992;32:529-33.

25 Hamburger SA, McEver RP. GMP-140 mediates adhesion Hamburger SA, McEver RP. GMP-140 mediates adhesion
of stimulated platelets to neutrophils. Blood 1990;75:550-4. of stimulated platelets to neutrophils. Blood 1990;75:550-4.
Larsen E, Celi A, Gilbert GE, Furie BC, Erban JK, Bonfanti Larsen E, Celi A, Gilbert GE, Furie BC, Erban JK, Bonfanti
R, et al. PADGEM protein: a receptor that mediates the interaction of activated platelets with neutrophils and monocytes. Cell 1989;59:305-12.

27 Asa D, Raycroft L, Ma L, Aeed PA, Kaytes PS, Elhammer $\mathrm{AP}$, et al. The P-selectin glycoprotein ligand functions as a common human leukocyte ligand for $\mathrm{P}$ - and E-selectins. $\mathcal{f}$ Biol Chem 1995;270:11662-70. 